\title{
Synthesis of Barium Nickel Titanium Oxide Stabilized by Citric Acid
}

\author{
K. Y. Chew, M. Abu Bakar*, N.H.H. Abu Bakar \\ Nanoscience Research Laboratory, School of Chemical Sciences, Universiti Sains Malaysia, 11800 USM Pulau Pinang, Malaysia. \\ Email: bmohamad@usm.my
}

Received 2012

\begin{abstract}
Barium nickel titanium oxide particles $\left(\mathrm{Ba}_{2} \mathrm{NiTi}_{5} \mathrm{O}_{13}\right)$ were synthesized in the presence of citric acid by using a two step sol-gel method followed by calcination. The addition of citric acid as a stabilizer (mole ratio of $0.5,1.0,2.0,4.0$ ) resulted in the formation of $\mathrm{Ba}_{2} \mathrm{NiTi}_{5} \mathrm{O}_{13}$ particles with various morphology (i.e. sphere, cube, rod). These various morphology changes were deduced to be caused by citric acid that tends to absorbed on certain dimension of the $\mathrm{Ba}_{2} \mathrm{NiTi}_{5} \mathrm{O}_{13}$ particles when different concentration of citric acid was added. Besides that, the growth of $\mathrm{Ba}_{2} \mathrm{NiTi}_{5} \mathrm{O}_{13}$ particles from incorporation of bulky micelles which act as a protective 'shell' that control particle sizes by attaching on the surfaces of particles.
\end{abstract}

Keywords: Barium Nickel Titanium Oxide; Citric Acid; Morphology

\section{Introduction}

Ceramic perovskite materials have gained a lot of interest because they are exploited as industrial electrodes [1], catalysts [2, 3], electronic components [4] and so on. The high demand for these materials is ascribed to their unique characteristics such as high mechanical strength, high temperature stability and lowered sintering temperature of ceramic materials as well as high surface area. Recently, perovskite structured metal oxides $\left(\mathrm{ABO}_{3}\right)$ has become a promising heterogenous catalyst as it provides features suitable for green sustainable technology [2,3] and also has high porosity which resulted in a better catalyst life [3]. The structure of perovskite ceramics $\left(\mathrm{ABO}_{3}\right)$ is where $\mathrm{A}$ is the larger cations from alkaline metal groups whereas $\mathrm{B}$ is the smaller cations from transition metal groups. Either site of $\mathrm{A} / \mathrm{B}$ or both cations are responsible for the respective catalytic reaction. Therefore, this material can reduce the usage amount of the commonly expensive noble metals such as $\mathrm{Pd}, \mathrm{Pt}$ and $\mathrm{Rh}$ [3]. Certain binary, ternary and quaternary metal oxides that contain 2, 3 and 4 different metal elements also belong to the perovskite-type mixed oxides materials. Barium nickel titanium oxide $\left(\mathrm{Ba}_{2} \mathrm{NiTi}_{5} \mathrm{O}_{13}\right)$ is an example of quaternary perovskite structured material [5].

Conventional solid state milling methods require high calcination temperatures and pressure, which can cause

\footnotetext{
*Corresponding author.
}

agglomeration of particles which in turn can cause the coarsening the surface of particles. This is undesirable as it can affect the chemical and physical properties of the particles $[6,7]$.

Therefore, many wet chemical synthesis methods have been introduced to compensate these problems such as hydrothermal [8], coprecipitation [9] molten salt route [10] and sol gel [11]. The sol gel method is a common wet chemical method because it exhibits several advantages such as low processing cost, excellent chemical homogeneity, low processing temperature as well as good stoichiometrically control of the elements of the synthesized compound. However, refined shaped and non agglomerated particles are commonly achieved by addition of supports which are then difficult to be removed. These supports such as polymers and surfactants have often been used in these supports assisted sol gel synthesis are able to control particles sizes and modify particles morphology [12]. However, total removal of carbonaceous substances by calcinations after the incorporation of these supports is difficult [12].

Citric acid stabilized sol gel method, which is commonly known as the Pechini method, are practiced by using citrate salts or mixtures of common salts with citric acids as precursor. This citrate will form complexations via its carboxylate groups with empty orbitals of metals [13]. Because of this, citric acid is well known as a stabilizer in nanoparticles synthesis by functioning as ligand, or acting as a particle surface modifier $[4,7,14]$. Therefore, the objective of this study is 
to investigate the effect of citric acid on the morphology of barium nickel titanium oxide particles prepared via a two steps of sol gel method.

\section{Methodology and Materials}

\subsection{Experimental}

Similar procedures for preparing barium nickel titanium oxide via the two steps sol gel method as discussed previously [15] was employed. However, in this experiment, citric acid $\left(\mathrm{C}_{6} \mathrm{H}_{8} \mathrm{O}_{7}, 99.5 \%\right.$, Merck $)$ was added in both steps after adding nickel acetate tetrahydrate and barium hydroxide monohydrate respectively. Half the amount of citric acid was added during the first step, and the other half amount of citric acid is added in the second step. Detail mole ratio of each reactant with designated sample numbering is tabulated in Table 1 .

Table 1. Details mole ratio of reactants used.

\begin{tabular}{ccccc}
\hline & \multicolumn{4}{c}{ Mole Ratio of Reactants } \\
\cline { 2 - 5 } $\begin{array}{c}\text { Designa- } \\
\text { tion }\end{array}$ & $\begin{array}{c}\mathrm{Ba}(\mathrm{OH})_{2} \cdot \mathrm{H}_{2} \\
\mathrm{O}\end{array}$ & $\begin{array}{c}\mathrm{NiAc}_{2} \cdot 4 \mathrm{H}_{2} \\
\mathrm{O}\end{array}$ & $\mathrm{Ti}\left(\mathrm{OPr}^{\mathrm{i}}\right)_{4}$ & $\begin{array}{c}\text { Citric } \\
\text { Acid }\end{array}$ \\
\hline Sample 1 & 1.2 & 1.2 & 1 & 0.5 \\
\hline Sample 2 & 1.2 & 1.2 & 1 & 1.0 \\
\hline Sample 3 & 1.2 & 1.2 & 1 & 2.0 \\
\hline Sample 4 & 1.2 & 1.2 & 1 & 4.0 \\
\hline
\end{tabular}

\subsection{Characterization}

X-Ray Diffraction (XRD) analysis was performed using a SIEMENS D5000 X-Ray Diffractometer with a monochromatic $\mathrm{Cu}-\mathrm{K} \alpha$ radiation filter in the $2 \theta$ range of 20-90 ${ }^{\circ}$. Fourier Transform Infrared (FTIR) spectra were obtained by scanning from $4000-400 \mathrm{~cm}^{-1}$ and the resolution employed was $4 \mathrm{~cm}^{-1}$ using a Perkin-Elmer System 2000 infrared spectrometer. The sample were coated with a thin layer of gold on the surface to prevent discharge and average size of synthesized $\mathrm{Ba}_{2} \mathrm{NiTi}_{5} \mathrm{O}_{13}$ was determined by Scanning Electron Microscopy (SEM) performed using a Leica Cambridge Stereoscan S360 operated at $15 \mathrm{kV}$.

\section{Results and Discussion}

\subsection{Structural Composition (XRD)}

The phase composition was investigated by using XRD, which is shown in Figure 1. All major peaks are attributed to barium nickel titanium oxide, and these peaks match with the JCPDS card number 01-086-0207. Some minor impurities attributed to the organic peaks of remaining citric acid are also observed. The phase of $\mathrm{Ba}_{2} \mathrm{NiTi}_{5} \mathrm{O}_{13}$ is monoclinic and there are 12 major peaks which are indicated at $2 \theta$ angles of $24.4 \mathrm{P} 529.014^{\circ}$, $29.806^{\circ}, 30.358^{\circ}, 31.562^{\circ}, 33.724^{\circ}, 37.486^{\circ}, 38.928^{\circ}$, $43.715^{\circ}, 43.980^{\circ}, 44.071^{\circ}$ and $46.385^{\circ}$ that are corresponding to $\langle-401>,<310>,<-311>,<-203\rangle,<112>$, $<311>,<-312>,<-113>,<601>,<-404>,<313>,<602>$ and $<020>$ respectively.

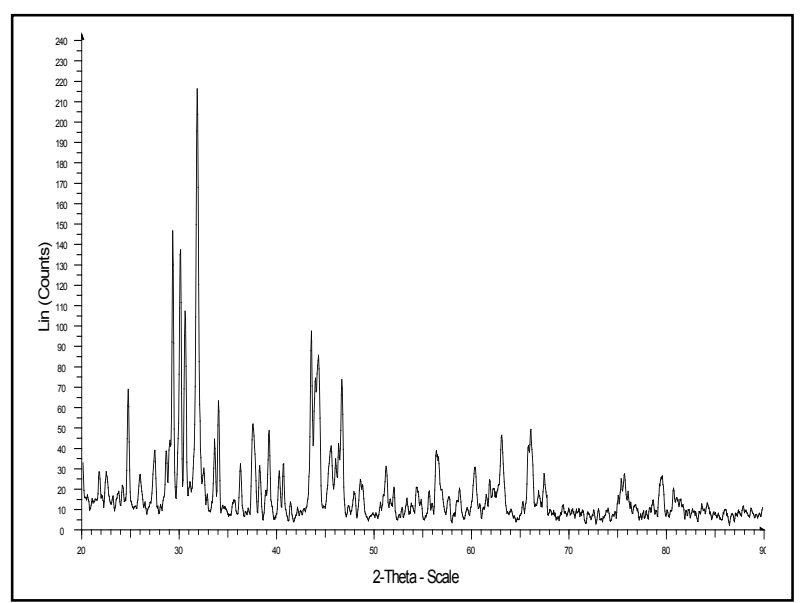

Figure 1. Typical XRD diffractogram of barium nickel titanium oxide stabilized by citric acid.

\subsection{Molecular Structure (FTIR)}

The effect of citric acid incorporation on the surface of barium nickel titanium oxide was investigated via FTIR and is shown in Figure 2. The FTIR spectra of citric acid (Figure 2(a)) is compared to the barium nickel titanium oxide incorporated with various amount of citric acid (Figure 2(b)-(e)). The spectra of citric acid demonstrate a broad band at $\sim 3590 \mathrm{~cm}^{-1}$ corresponding to the stretching vibration of $\mathrm{OH}$ group from citric acid. Sharp splitting bands at wavenumbers of 2360 and $2334 \mathrm{~cm}^{-1}$ due to the vibration bands from $\mathrm{C}-\mathrm{H}$ stretching mode of citric acid are also observed [16]. Besides, stretching bands at wavenumbers of 1810 and $1513 \mathrm{~cm}^{-1}$ which correspond to asymmetric and symmetric stretching vibrations of carboxylate $\left(\mathrm{COO}^{-}\right)$from bidendate ligand citric acid respectively are also available [16]. Other smaller vibration bands observed are also the stretching bands of the organic substances.

FTIR spectrum of neat $\mathrm{Ba}_{2} \mathrm{NiTi}_{5} \mathrm{O}_{13}$ has been reported in [15]. Upon incorporation of $\mathrm{Ba}_{2} \mathrm{NiTi}_{5} \mathrm{O}_{13}$ with citric acid as shown in Figure 2(b)-(e), the broad vibration bands to wavenumbers of $3433-3470 \mathrm{~cm}^{-1}$ occurs. This is due to the possibility of absorption of moisture from $\mathrm{KBr}$ pellet. Besides, some vibration bands corresponding to citric acid are not observed. However, those asymmetric and symmetric stretching vibration representing vibration bands of carboxylate $\left(\mathrm{COO}^{-}\right)$from carbonate are corresponding to $1670 \mathrm{~cm}^{-1}$ and $1432 \mathrm{~cm}^{-1}$ wavenumbers respectively as observed in Figure 2(b)-(e). These carbo- 
nate bands formed from calcination of citric acid with addition of $\mathrm{Ba}_{2} \mathrm{NiTi}_{5} \mathrm{O}_{13}$. This may indicate that incorporation of citric acid on $\mathrm{Ba}_{2} \mathrm{NiTi}_{5} \mathrm{O}_{13}$ particles by forming complexation has occurred previously before calcination [16]. In addition, $857 \mathrm{~cm}^{-1}$ wavenumber are corresponded to asymmetric stretching of carbonate [15]. Formation of carbonate in $\mathrm{Ba}_{2} \mathrm{NiTi}_{5} \mathrm{O}_{13}$ even after calcinations may be due to incomplete calcinations of organic substances in those samples. On the other hand, a broad absorption at wavenumber $\sim 540 \mathrm{~cm}^{-1}$ represents characteristic stretching vibration of Ti-O from perovskite phase structure formation as in $\mathrm{Ba}_{2} \mathrm{NiTi}_{5} \mathrm{O}_{13}$ [17] can also be observed. Therefore, incorporation of citric acid on $\mathrm{Ba}_{2} \mathrm{NiTi}_{5} \mathrm{O}_{13}$ has occurred.

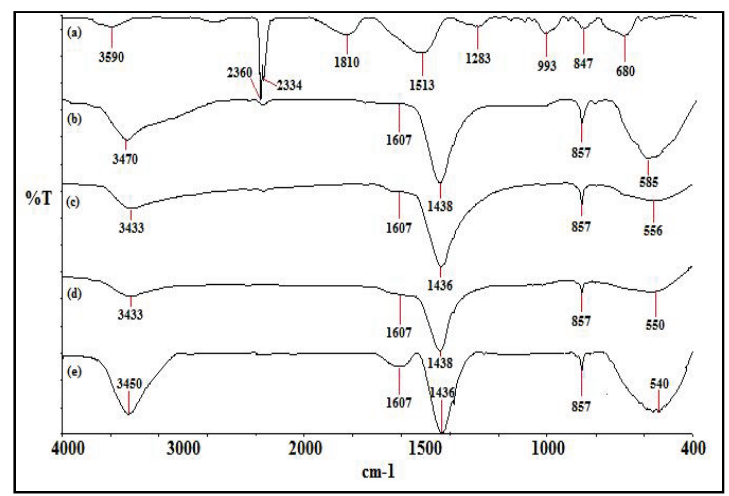

Figure 2. FTIR spectra of (a) citric acid; (b) Sample 1; (c) Sample 2 (d) Sample 3 and (e) Sample 4 after calcination at $900{ }^{\circ} \mathrm{C}$ for 8 hours.

\subsection{Morphology of $\mathrm{Ba}_{2} \mathrm{NiTi}_{5} \mathrm{O}_{13}(\mathrm{SEM})$}

The morphology of citric acid stabilized $\mathrm{Ba}_{2} \mathrm{NiTi}_{5} \mathrm{O}_{13}$ is not homogeneously spherical as observed for the neat $\mathrm{Ba}_{2} \mathrm{NiTi}_{5} \mathrm{O}_{13}$ [15]. In Sample 1 which is shown in Figure 3 , when the mole ratio of citric acid used is 0.5 , cubic shaped of $\mathrm{Ba}_{2} \mathrm{NiTi}_{5} \mathrm{O}_{13}$ particles were formed. An inhomogeneous size of particles existed (average size $=$ $0.78 \pm 0.56 \mu \mathrm{m})$. By continuously increasing the mole ratio of citric acid to 1.0 (Sample 2) as shown in Figure 4, the particles formed is still cubic shaped however with better size distribution $(0.35 \pm 0.13 \mu \mathrm{m})$. When the mole ratio of citric acid is 2.0 (Sample 3 ) as shown in Figure 5, some small cubic shaped particles still exist (average size $=0.31 \pm 0.18 \mu \mathrm{m}$ ) however most of the particles are in the form of rods with an average length $7.01 \pm 3.19 \mu \mathrm{m}$. By adding citric acid up to a mole ratio of 4.0 (Sample 4) which is shown in Figure 6, neither cube shape nor rod shape particles can be seen. Instead spherical shaped particles with an average size of $0.60 \pm 0.39 \mu \mathrm{m}$ particles are observed.

The particles size transformation of barium nickel titanium oxide with increasing amount of citric acid as stabilizer can be explained according to the 'protective shell' concept. When the amount of citric acid increases, the precursor nuclei are repulsed by the increasing amount of steric hindrance from the long carbon chain of citric acid. Thus, the precursor nuclei are forced apart before they have the chance to collide with each other and form bigger precursor nuclei. Therefore, the larger the amount of citric acid, the smaller the particles formed. Nevertheless, the spherical particle sizes are larger than the non-citric acid incorporated on $\mathrm{Ba}_{2} \mathrm{NiTi}_{5} \mathrm{O}_{13}$ particles reported in [15]. In this case, citric acid may be facilitating formation of bigger micelles and thus bigger particles as compared to non-citric acid incorporated $\mathrm{Ba}_{2} \mathrm{NiTi}_{5} \mathrm{O}_{13}$ particles as the formation of them do not need to be restricted by the micelles.

Citric acid is believed to act as a surfactant. When dissolved in water, surfactant attracts with each other to form micelles. These micelles are the core center of particles formation. As observed, the morphology transformation of barium nickel titanium oxide occurred with different amounts of citric acid. Lower amounts of citric acid addition helped the surfactant to form rod shaped particles. Nevertheless, when the amount of citric acid increases high enough as in Sample 4, citric acid tends to form spherical micelles that facilitate the formation of spherical particles. Citric acid may be tends to absorbed on certain dimension of $\mathrm{Ba}_{2} \mathrm{NiTi}_{5} \mathrm{O}_{13}$ particles when different amount of citric acid is added. When the mole ratio of citric acid is $0.5 \%$, citric acid is absorbed on both horizontal and vertical axial forming cubic shaped $\mathrm{Ba}_{2} \mathrm{NiTi}_{5} \mathrm{O}_{13}$ particles. As increasing the citric acid concentration, the increased amount of citric acid tends to absorbed more on horizontal dimension and thus forming rod shaped $\mathrm{Ba}_{2} \mathrm{NiTi}_{5} \mathrm{O}_{13}$ particles. However, when the mole ratio of citric acid increases to $4.0 \%$, the excess of citric acid are absorbed on every dimension of $\mathrm{Ba}_{2} \mathrm{NiTi}_{5} \mathrm{O}_{13}$ particles and thus forming many smaller and spherical shaped particles. Figure 7 shows the tentative schematic diagram of these morphology changes of $\mathrm{Ba}_{2} \mathrm{NiTi}_{5} \mathrm{O}_{13}$ particles. Therefore, citric acid is not only able to control the size of $\mathrm{Ba}_{2} \mathrm{NiTi}_{5} \mathrm{O}_{13}$ particles, but also able to control the morphology of particles.

\section{Conclusion}

Complexation of citric acid incorporation on $\mathrm{Ba}_{2} \mathrm{NiTi}_{5} \mathrm{O}_{13}$ was found to occur. Formation of a protecting shell of citric acid was deemed to be able to stabilize as well as modify the morphology of core barium nickel titanium oxide particles. Rod shaped or cubic shaped particles formed when small amount of citric acid was used. However, when the citric acid content was increased to 4.0 mole $\%$, more homogenous and nearly spherical particles with an average size of $0.60 \pm$ $0.39 \mu \mathrm{m}$ were observed. 


\section{Acknowledgements}

This work is financially supported by the USM Research University Postgraduate Research Grant Scheme (RUPGRS). Great appreciation is given to USM Fellowship and to lab technicians for helping in operating instruments and equipments.

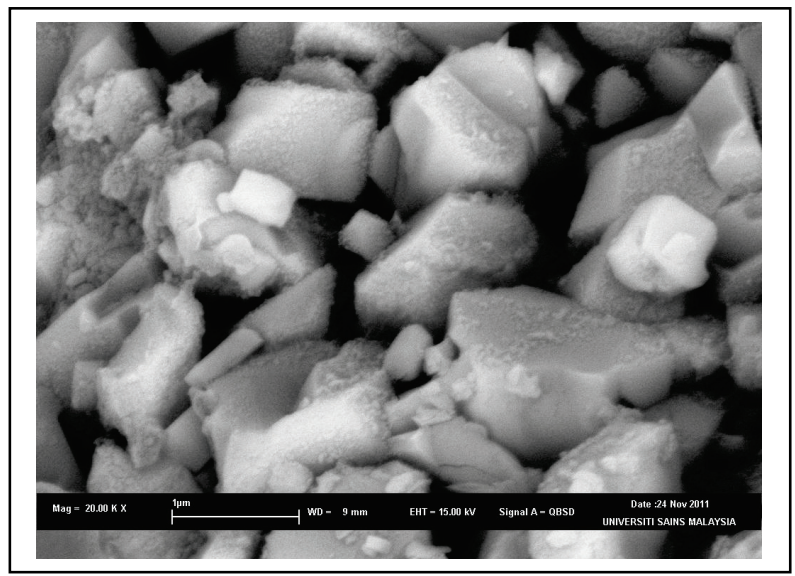

Figure 3. SEM micrograph of Sample 1 magnified 20000 times.

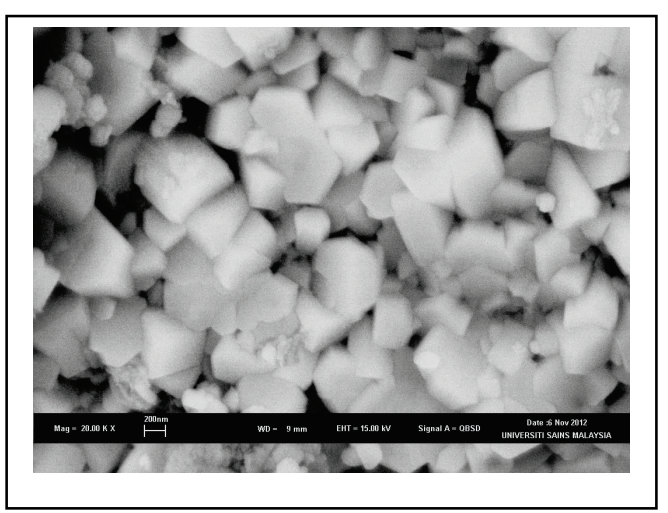

Figure 4. SEM micrograph of Sample 2 magnified 20000 times.

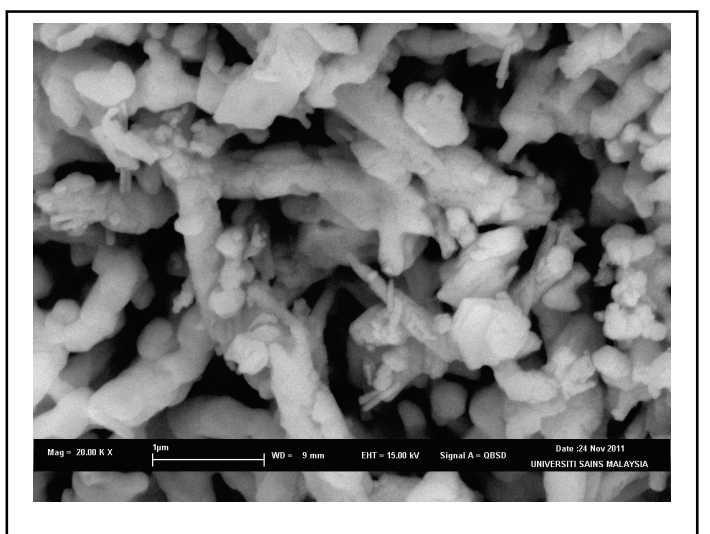

Figure 5. SEM micrograph of Sample 3 magnified 20000 times.

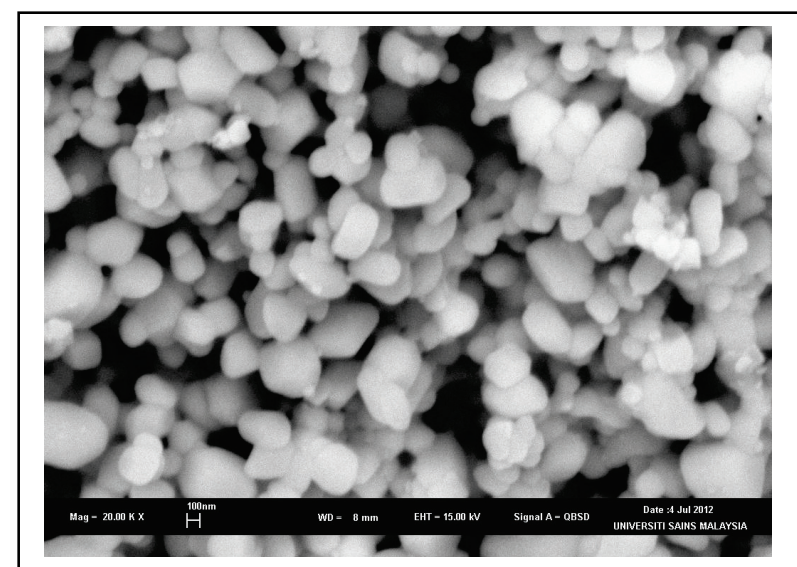

Figure 6. SEM micrograph of Sample 4 magnified 20000 times.

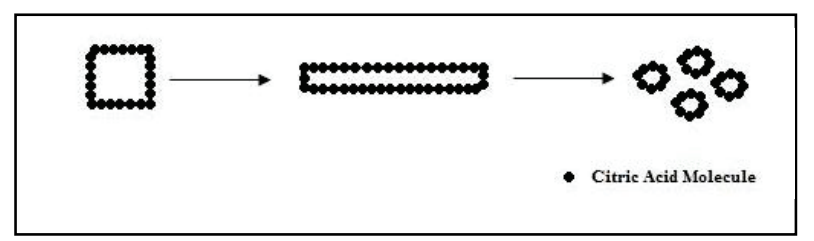

Figure 7. Tentative schematic diagram for morphology changes of $\mathrm{Ba}_{2} \mathrm{NiTi}_{5} \mathrm{O}_{13}$ particles.

\section{REFERENCES}

[1] Y. Shimizu and N. Yamashita, "Solid Electrolyte $\mathrm{CO}_{2}$ sensor using NASICON and Perovskite-Type Oxide Electrode", Sensors and Actuators, Vol. B62, 2000, pp. 102-106.

[2] B. Seyfi, M. Baghalha and H. Kazemian, "Modified La$\mathrm{CoO}_{3}$ Nano-Perovskite Catalysts for the Enviromental Application of Automotive CO Oxidation", Chemical Engineering Journal, Vol. 148, 2009, pp. 306-311.

[3] M. Misono, “ Recent Progress in the Practical Applications of Heteropolyacid and Perovskite Catalysts: Catalytic Technology for the Sustainable Society", Catalysis Today, Vol. 144, 2009, pp. 285-291.

[4] Z.Ž. Lazarević, M. Vijatović, Z. Dohčević-Mitrović, N.Ž. Romčević, M.J. Romčević, N. Paunović and B.D. Stojanović, "The Characterization of the Barium Titanate Ceramic Powders Prepared by the Pechini Type Reaction Route and Mechanically Assisted Synthesis", Journal of European Ceramic Society, Vol. 30, 2010, pp. 623-628.

[5] R.D. Adams, R. Layland and C. Payen, "A New Mixed-Metal Titanate. The Synthesis and Characterization of $\mathrm{Ba}_{2} \mathrm{NiTi}_{5} \mathrm{O}_{13}$ ", Chemistry of Materials, Vol. 7, 1995, pp. 2168-2170.

[6] A.C. Caballero, J.F. Fernández, C. Moure, P. Durán and Y.-M. Chiang, "Grain Growth Control and Dopant Distribution in $\mathrm{ZnO}-$ Doped $\mathrm{BaTiO}_{3}$ ", Journal of American Ceramic Society, Vol. 81, 1998, pp. 939-944.

[7] V. Vinothini, P. Singh and M. Balasubramanian, "Synthesis of Barium Titanate Nanopowder Using Polymeric 
Precursor Method", Ceramic International, Vol. 32, 2006, pp. 99-103.

[8] M.Z.-C. Hu, V. Kurian, E.A. Payzant, C.J. Rawn, and R.D. Hunt, "Wet-Chemical Synthesis of Monodispersed Barium Titanate Particles - Hydrothermal Conversion of $\mathrm{TiO}_{2}$ Microspheres to Nanocrystalline $\mathrm{BaTiO}_{3}$ ", Powder Technology, Vol. 110, 2000, pp. 2-14.

[9] S.K. Lee, T.J. Park, G.J. Choi, K.K. Koo and S.W. Kim, "Effects of $\mathrm{KOH} / \mathrm{BaTi}$ and $\mathrm{Ba} / \mathrm{Ti}$ ratios on Synthesis of $\mathrm{BaTiO}_{3}$ Powder by Coprecipitation/Hydrothermal Reaction”, Materials Chemistry and Physics, Vol. 82, 2003, pp. 742-749.

[10] Y. Zhang, L. Wang and D. Xue, "Molten Salt Route of Well Dispersive Barium Titanate Nanoparticles", Powder Technology, Vol. 217, 2012, pp. 629-633.

[11] S. Sreekantan, A.F.M. Noor, Z.A. Ahmad, R. Othman and A. West, "Structural and Electrical Characteristic of Crystalline Barium Titanate Synthesized by Low Temperature Aqueous Method", Journal of Materials Processing Technology, Vol. 195, 2008, pp. 171-177.

[12] S. Zhang, F. Jiang, G. Qu, and C. Lin, "Synthesis of Single-Crystalline Perovskite Barium Titanate Nanorods by A Combine Route Based on Sol-Gel and Surfactant-Templated Methods", Materials Letters, Vol. 62,
2008, pp. 2225-2228.

[13] A. Abreu Jr, S.M. Zanetti, M.A.S. Oliveira and G.P. Thim, "Effect of Urea on Lead Zirconate Titanate- $\mathrm{Pb}\left(\mathrm{Zr}_{0.52} \mathrm{Ti}_{0.48}\right) \mathrm{O}_{3}$-Nanopowders Synthezied by the Pechini Method", Journal of the European Ceramic Society, Vol. 25, 2005, pp. 743-748.

[14] K.K. Lee, Y.C. Kang, K.Y. Jung and J.H. Kim, "Preparation of Nano-Sized $\mathrm{BaTiO}_{3}$ Particle by Citric Acid-Assisted Spray Pyrolysis", Journal of Alloys and Compounds, Vol. 395, 2005, pp. 280-285.

[15] K.Y. Chew, M. Abu Bakar, "Two Steps Synthesis of Quaternary Metal Titanate of $\mathrm{Ba}_{2} \mathrm{NiTi}_{5} \mathrm{O}_{13}$ and Characterization", Advanced Materials Research, Vol. 364, 2012, pp. 353-358.

[16] A. Hardy, J.D’ Haen, M.K. Van Bael and J. Mullens, “An Aqueous Solution-Gel Citratoperoxo-Ti(IV) Precursor: Synthesis, Gelation, Thermo-Oxidative Decomposition and Oxide Crystallization", Journal of Sol-Gel Science and Technology, Vol. 44, 2007, pp. 65-74.

[17] W.-D. Yang, K.-M. Hung and C.-F. Kao, "Preparation and Dielectric Properties of Semiconducting Lanthanum-Doped Strotium Ttitante Ceramics from Titanyl Citrate Precursors", Ceramics International, Vol. 26, 2000, pp. $475-484$. 